LICENÇA CC BY: Artigo distribuído sob os termos

Creative Commons, permite uso e distribuição irrestrita em qualquer meio desde que o autor credite a fonte original.

\title{
O CONTEXTO PROFISSIONAL NOS CURSOSDE PEDAGOGIA A PARTIRDE UMA PERSPECTIVA INTEGRADA DA FORMAÇÃO
}

\author{
THE PROFESSIONAL CONTEXT IN PEDAGOGY \\ COURSES FROM ANINTEGRATED PERSPECTIVE OF TRAINING \\ EL CONTEXTO PROFESIONAL EN LAS CARRERAS DE PEDAGOGÍA \\ A PARTIR DE UNA PERSPECTIVA INTEGRADA DE LA FORMACIÓN \\ Helena Maria dos Santos Felício ${ }^{1}$ \\ ${ }^{1}$ Doutora em Educação (Currículo) pela PUC/SP.
}

Docente do Programa de Pós-Graduação em Educação da Universidade Federal de

Alfenas (UNIFAL), Alfenas, MG, Brasil.

Resumo: Este trabalho tem por objetivo analisar o significado que os contextos de atuação profissional assumem no processo de formação inicial dos professores, especificamente, nos cursos de Pedagogia do Brasil, tendo como referência uma perspectiva integrada da formação. De caráter qualitativo, analisamos os Projetos Pedagógicos dos referidos cursos por meio da Análise de Conteúdo, a partir de três indicadores: (a) concepção do contexto profissional; (b) relação estabelecida com o contexto profissional; e (c) construção de comunidades de práticas. Os resultados evidenciaram avanços no que diz respeito à concepção do contexto de atividade profissional e da relação estabelecida com o contexto de atividade profissional, embora sejam necessárias ações e iniciativas mais incisivas tanto da Universidade quanto das Escolas de Educação Básica, de modo que os futuros professores possam saber administrar os diferentes saberes, construídos em diferentes lugares.

Palavras-Chave: Formação Inicial; Contextos Profissionais; Relação Universidade-Escola.

Abstract: This work analyzes the meaning assumed by contexts of professional practice in the initial teacher training process, specifically in Brazilian Pedagogy courses, taking as its reference an integrated perspective of training. Characterized as qualitative research, it analyzes the pedagogical projects of the courses in question using content analysis, based on three indicators: (a) concept of professional context; (b) established relationship to professional context and (c) the construction of practical communities. The results demonstrate advances in relation to the concept of professional activity context and the established relationship to the professional context, but more incisive actions and initiatives are needed, both for Universities and schools, so that future teachers can know how to administrate different forms of knowledge, constructed in different places.

Keywords: Initial Training; Professional Contexts; University-School Relations.

Resumen: Este trabajo tiene por objetivo analizar el significado que los contextos de actuación profesional asumen en el proceso de formación inicial de los profesores, específicamente, en las carreras de Pedagogía en Brasil, teniendo como referencia una perspectiva integrada 
de la formación. De carácter cualitativo analizamos los Proyectos pedagógicos de dichas carreras a través del Análisis de Contenido, a partir de tres indicadores: (a) concepción del contexto profesional; (b) relación establecida con el contexto profesional y (c) la construcción de comunidades de prácticas. Los resultados evidenciaron avances en lo que se refiere a la concepción del contexto de actividad profesional y de la relación establecida con el contexto de actividad profesional, aunque se necesitan acciones e iniciativas más incisivas tanto de la Universidad y de las Escuelas de Educación Básica, de modo que los futuros profesores, puedan saber administrar los diferentes saberes, construidos en diferentes lugares.

Palabras clave: Formación Inicial; Contextos Profesionales; Relación Universidad-Escuela.

\section{Introdução}

Este trabalho tem por objetivo analisar o significado que os contextos de atuação profissional assumem no processo de formação inicial dos professores, especificamente, nos cursos de Pedagogia do Brasil, tendo como referência uma perspectiva integrada da formação.

Diante dos encaminhamentos políticos e econômicos que assistimos nos últimos anos que fragilizam a área educacional e, consequentemente, os processos formativos nos diferentes níveis e modalidades, vivenciamos problematizações no campo da formação de professores que colocam em "questão" a qualidade da formação deste profissional e, na sequência, de sua atuação no contexto de trabalho.

Acompanhamos dois movimentos que se antagonizam e que possuem relações direta com este trabalho: O primeiro diz respeito à elevação de carga horária destinada à prática pedagógica e aos estágios nos cursos de formação inicial de professores, estabelecida pelas últimas Diretrizes Curriculares Nacionais para a Formação de Professores (BRASIL, 2015), como uma ação que se basta em si mesma.

O segundo diz respeito a movimentos "ocultos", embora intencionais, a favor da naturalização da formação dos professores como um processo simples e linear, bem como da tendência de minimização desta formação em termos do desenvolvimento curricular, que debilitam a formação inicial de professores e acentuam a desqualificação social deste profissional, tornando até possível a aceitação de profissionais com "notório saber" para a função docente.

Entretanto, como formadora de professores, colocamo-nos na defesa de um processo formativo que seja capaz de contribuir com a construção de uma profissionalidade docente preparada para: atuar de forma crítica no contexto social e educacional; agir como sujeito mediador na construção de um conhecimento significativo; contribuir para com a formação do indivíduo e seu posicionamento no contexto social; dar respostas assertivas aos desafios formativos dos estudantes, sobretudo na perspectiva do seu desenvolvimento humano. Defendemos uma formação que valoriza a construção do conhecimento profissional docente, que se constitui em um processo complexo por natureza e que se constrói a partir de dimensões relacionais 
entre conhecimentos, sujeitos, situações e contextos.

No âmbito dessas diferentes dimensões relacionais, delimitamos para este trabalho um olhar mais restrito para a dimensão dos "contextos", pela qual se estabelecem vínculos entre o "saber" e "saber fazer profissional", entre a "Universidade" e a "Escola de Educação Básica", entre o "espaço de conhecimento acadêmico" e o "espaço do conhecimento de atuação profissional", ainda no período da formação inicial.

Para Zeichner (2010), a separação entre esses dois universos, muitas vezes interpretada como distanciamento entre a teoria e prática, é um problema central na formação de professores que perdura há décadas. Entretanto, o autor advoga que, para a construção da profissionalidade docente, faz-se necessário um conhecimento profissional construído a partir da academia e, também, um conhecimento construído a partir do contexto de atuação profissional docente. Ou seja, não se trata de situações distintas, mas da compreensão da existência de um "terceiro espaço", como espaço híbrido resultante da alternância entre os sujeitos e as situações que estão presentes nestes dois contextos, a partir de relações pessoais e profissionais menos hierárquicas.

O processo de formação de professores no Brasil, sobretudo após a promulgação das Diretrizes Curriculares Nacionais para a Formação de Professores da Educação Básica (BRASIL, 2002; 2015), acentua a necessidade de que a formação de professores se efetive a partir de uma estreita relação entre o campo de formação e o campo de atuação profissional, ou seja, entre a Universidade e a Escola.

Assim, como afirma Felício (2014), as relações entre esses contextos, na formação inicial de professores, devem ser entendidas como dimensões de um mesmo processo que abarca relações de desafios, de descobertas, de (res)significação, de construções, de formação compartilhada, vivenciadas em diversos "espaços e tempos" organizados em situações distintas que podem parecer independentes, mas que são profundamente indissociáveis. Ou seja, é impossível considerar um sem o outro.

Não temos dúvida de que, na formação inicial de professores, a relação entre a Universidade e a Escola deve ser estabelecida a partir um status mais igualitário entre essas duas instituições, até para podermos, conforme indica Nóvoa (2009), fazer com que a formação inicial de professores seja construída, também, dentro da profissão, uma vez que é na escola e com os outros professores, na dimensão da docência compartilhada, que aprendemos a profissão e a cultura profissional docente. Para o autor, essa dimensão é fundamental no processo inicial de formação, argumentando que é preciso conceder "aos professores mais experientes um papel central na formação dos mais jovens." (NÓVOA, 2009, p. 36).

Nesta ótica, o processo formativo passa a ser construído em uma perspectiva integrada da formação e no contexto de responsabilidade profissional docente que reconhece e valoriza tanto o conhecimento construído na universidade quanto o conhecimento construído no contexto de atuação profissional. 
Reconhecendo que o status social da Universidade colabora para que a mesma se coloque em posição de superioridade em relação à Escola de Educação Básica, entendemos que iniciativas para uma relação mais igualitária e menos hierárquica entre essas instituições, na formação inicial de professores, possam ser assumidas, primeiramente, pela Universidade, como instituição que legitima a formação.

Deste modo, constituído como parte de uma pesquisa mais ampla, desenvolvida em nível de pós-doutoramento, que analisou as dimensões integradoras dos currículos dos cursos de Pedagogia do Brasil, este trabalho tem por objetivo analisar os significados que os contextos de atuação profissional assumem no processo de formação inicial dos professores, nomeadamente, nos cursos de Pedagogia do Brasil, mediante a análise de seus Projetos Pedagógicos, tendo como referência uma perspectiva integrada da formação.

\section{O contexto profissional na perspectiva integrada da formação}

As exigências da sociedade, cada vez mais complexas, constituídas sobre o acesso, o domínio e a produção do conhecimento, questionam a escola quanto às suas funções e as desafiam no sentido de se transformarem, constantemente, a fim de que o seu papel social seja cumprido. Consequentemente, essas mesmas exigências demandam professores cada vez mais competentes, adaptados e capazes, profissionalmente, para responderem a tais exigências.

Este cenário instiga permanentemente o campo da formação de professores, sobretudo a inicial, no que diz respeito à qualidade dos processos formativos desenvolvidos pelas instituições formadoras e que não podem ser considerados de forma isolada. Tais processos devem ir ao encontro do perfil de professor necessário aos contextos atuais, o qual deve assumir a profissão como um serviço social e humano; que construa, permanentemente, conhecimentos e habilidades para desempenhar suas funções de fazer o outro aprender; que seja capaz de estabelecer relações pessoais e profissionais com os educandos; e que seja comprometido e responsável com o desenvolvimento de um trabalho coletivo com seus pares (MUÑOZ, 2006, p. 34-42).

No caso específico do currículo de formação inicial de professores, apesar de encontrarmos avanços, no que diz respeito à conceitualização e às práticas construídas pelas instituições formadoras, evidenciamos autores que apresentam entraves e limitações destes currículos.

Formosinho (2009), embora reconheça as positividades do ato de elevar a formação inicial dos professores ao nível superior, transcorrido nas últimas décadas do século passado, indica a "academização" como um problema a ser enfrentado neste processo formativo, uma vez que acentuou a formação teórica, afastada das preocupações práticas e complexas do contexto de trabalho que se configuram como componentes 
profissionalizantes da formação. Ainda, Estrela e Estrela (2001) indicam que um modelo formativo caracterizado pela supremacia da teoria sobre a prática, em que esta última é assumida como forma de "aplicação" da primeira, provoca efeitos perversos no processo de formação, uma vez que o mesmo leva à desvalorização e à distorção dos elementos teóricos, ampliando as ambiguidades existentes entre a formação inicial e o exercício profissional dos professores, bem como conservando a distância conceitual, espacial e temporal entre os contextos de formação e os contextos de trabalho.

No âmbito deste trabalho, podemos considerar que os cursos de Pedagogia, a partir da promulgação de suas Diretrizes Curriculares Nacionais (BRASIL, 2006), assumem a responsabilidade da formação inicial de professores para a Educação Infantil e primeiro ciclo do Ensino Fundamental, reconhecendo, conforme explicita o artigo $3^{\circ}$, como elementos centrais o conhecimento da escola como organização complexa, a pesquisa no campo educacional e a participação na gestão dos processos educativos. No entanto, para a consecução destes princípios formativos, entendemos que o processo de formação inicial deve ser desenvolvido a partir de uma proposta que sustente a relação entre a Universidade e a Escola de Educação Básica, de modo que ambos os contextos possam se assumir como instância formativa profissional para os licenciandos. Deste modo, entendemos que a perspectiva integrada da formação pode ser assumida como aquela capaz de favorecer tal processo. Tal perspectiva tem a ver com a forma como os

Diferentes componentes da formação (Ciências da Educação/Ciências da Especialidade/Prática Profissional) se articulam no sentido de adquirirem uma coerência, que permita aos professores em formação encontrar um significado pessoal e profissional, de forma a, progressivamente, irem construindo as teorias práticas que poderão orientar a sua ação. (ALONSO; SILVA, 2005, p. 43).

Para além desta articulação entre os diferentes componentes da formação, a perspectiva integrada também considera imprescindível a construção de uma "visão praxiológica do saber profissional" (ALONSO, 2007, p. 46), que se constrói fundamentalmente nos contextos em que se exerce a prática docente, ratificando, desta maneira, a necessidade de o processo formativo estar imbricado com o contexto de atuação profissional. Desta forma, integrar o contexto de formação e o contexto de trabalho no processo formativo inicial dos professores supõe superar as atuais configurações curriculares que indicam, no decorrer de tal processo: momentos distintos para a "formação teórica" e para a "formação prática"; status diferenciados para a Universidade e para a Escola de Educação Básica; com o objetivo de investir na construção de um projeto global, integrado, que dê um sentido formativo coerente e que fundamente as ações no exercício profissional, como afirma Roldão no seguinte excerto:

Uma implicação para a formação tem a ver com a necessidade de centrar a formação na ação profissional, na ação de ensinar, como eixo organizador de toda a formação, ou seja, não conceber os planos dos cursos de formação como um mosaico, uma soma de partes desligadas, mas como um projeto organizado em torno da função e do saber necessários ao desempenho profissional, que é aquilo que lhe dá sentido. (ROLDÃO, 2007, p. 40).

Tal implicação não corresponde à submissão do processo de formação à lógica de satisfação imediata das necessidades e das dificuldades apresentadas pelos professores 
em seus contextos de trabalho (MUÑOZ, 2006, p. 45), mas de assumir a complexa realidade de tais contextos como elemento formativo para o desenvolvimento profissional os quais garantam sentido à formação. O que exige não só a alternância realizada pelos estudantes, futuros professores, mas também dos professores formadores que, quanto mais imersos nos contextos de atividade profissional docente, mais significado podem conferir ao processo de formação e à sua ação formadora.

Desta forma, considerando as tendências contemporâneas que demandam este estreitamento relacional significativo entre a formação e o exercício da profissionalidade, como indica Flores (2010), há de se considerar que as diversas dimensões do desempenho docente nos contextos educacionais reais precisam estar incluídas no processo de formação inicial dos professores.

\section{Percurso metodológico do estudo}

Para compreender o significado que os contextos de atuação profissional assumem no processo de formação inicial dos professores nos cursos de Pedagogia, a partir de uma perspectiva integrada da formação, procedemos à análise dos Projetos Pedagógicos de alguns cursos de Pedagogia, por entender que esses documentos expressam, como currículo prescrito, as intenções formativas dos cursos.

No entendimento de que o currículo prescrito é um instrumento definidor de percursos formativos, ordenador dos conteúdos, orientador de metodologias e norteador das práticas pedagógicas (SACRISTÁN, 2010), inferimos que ele deve estar na base e no desenvolvimento de todo e qualquer curso, a fim de lhe garantir dinamicidade e coerência na formação da qual ele é a expressão material, não com a ausência de tensões, uma vez que ele também é um instrumento de poder.

Desta forma, elegemos os Projetos Pedagógicos de alguns cursos de Pedagogia como corpus de análise por entendê-los como um instrumento conceitual e organizativo que legitima suas opções teóricas e suas intenções, ao mesmo tempo em que explicita suas estruturas, suas decisões curriculares e suas práticas. No dizer de Roldão,

Considerar o projeto nesta dupla e ambivalente inserção em campos tão diversos como o epistemológico e o organizacional, para podermos aumentar a inteligibilidade e a mobilização eficaz deste poderoso instrumento conceitual: de um lado a sua valia como forma de conceitualização do saber e da ação, e de outro o seu potencial como instrumento de gestão e intencionalização da atividade. (ROLDÃO, 2001, p. 16).

Cientes de que o Projeto Pedagógico de um determinado curso, e neste caso de Pedagogia, deve se configurar como instrumento com esta dupla ambivalência, a epistemológica e organizativa, sua análise, neste trabalho, é relevante, uma vez que intenciona compreender o significado que ele atribui aos contextos de atuação profissional.

Este estudo está fundamentado em uma abordagem qualitativa de pesquisa que supõe a compreensão do objeto na sua "complexidade e inteireza, integrados no seu 
contexto" (FLICK, 2005, p. 5), a partir de uma relação dinâmica entre o sujeito e este objeto, em que o estudo é construído a partir de um "ir e vir" entre a teoria, o corpus de análise da pesquisa e o seu contexto mais amplo.

Assumindo que os Projetos Pedagógicos dos cursos de Pedagogia são instrumentos reveladores de opções realizadas por sujeitos, em determinados contextos, que indicam as referências conceituais e organizacionais para a formação de professores, privilegiamos a análise documental como procedimento para a coleta de informações.

A análise desses projetos confere legitimidade à investigação, uma vez que os mesmos nos remetem ao conhecimento, na perspectiva oficial, declarada por opções institucionais no que diz respeito à formação de professores nestes cursos. Eles são elaborados a partir de exigências legais, contudo manifestam interesses, valores e concepções que foram, cuidadosamente, selecionados para estarem ali e, portanto, revelam as intenções políticas, epistemológicas, curriculares e formativas designadas pelo conjunto de pessoas que os elaboraram, em consonância com os objetivos fins da própria instituição.

Desta forma, tomar os Projetos Pedagógicos desses cursos como objeto de análise é reconhecer seu potencial elucidativo, que, neste caso, refere-se aos significados dos contextos de atuação profissional, implícito ou explicitamente declarados. E cientes de que a análise documental é um "processo de garimpagem" (PIMENTEL, 2001), várias garimpagens foram necessárias.

A primeira garimpagem diz respeito à seleção dos projetos a serem analisados. Reconhecendo o grande número de Instituições de Ensino Superior no Brasil, fizemos a opção por selecionar o universo das Universidades Federais Brasileiras. No entanto, considerando o total de 63 instituições neste universo, limitamos nossa amostra em $40 \%$ das universidades de cada região do país. Essa porcentagem foi estabelecida para que a região que possuía o menor número de universidades fosse contemplada com, pelo menos, duas instituições na amostra.

Em um primeiro momento, o trabalho pretendia ser desenvolvido com a seguinte amostragem definida aleatoriamente por sorteio: 02 na Região Centro-Oeste, 07 na Região Nordeste, 04 na Região Norte, 08 na Região Sudeste e 05 na Região Sul. No entanto, para manter o princípio da homogeneidade (BARDIN, 2013), realizamos a exclusão de 06 instituições por apresentarem cursos com aspectos diferenciados das demais. Assim, o corpus documental para análise ficou definido deste modo: 02 na Região Centro-Oeste (A-1 e A-2), 04 na Região Nordeste (B-1, B-2, B-3 e B-4), 02 na Região Norte (C-1 e C-2), 07 na Região Sudeste (D-1, D-2, D-3, D-4, D-5, D-6 e d-7) e 05 na Região Sul (E-1, E-2, E-3, E-4 e E-5), totalizando 20 instituições.

De cada Universidade selecionada recolhemos o Projeto Pedagógico do Curso de Pedagogia, que foi tomado como uma Unidade de Contexto (UC). Os mesmos foram objeto de leituras para a seleção e organização de registros considerados significativos e pertinentes de serem codificados e analisados (ESTEVES, 2006). 
A organização destes registros constituiu-se na segunda garimpagem, uma vez que tais elementos significativos estão presentes nos documentos e "precisam ser encontrados, receber um tratamento que, orientado pelo problema proposto pela pesquisa, estabeleça a montagem das peças, como num quebra-cabeça". (PIMENTEL, 2001, p. 180).

Os registros foram selecionados a partir de um núcleo central de análise que corresponde ao significado atribuído ao contexto de atuação profissional. Dos registros emergiram os seguintes indicadores que contribuíram para a compreensão do objeto em análise: (a) concepção do contexto profissional; (b) relação estabelecida com o contexto profissional e (c) construção de comunidades de práticas formativas.

Em seguida, a análise de conteúdo, entendida como "conjunto de técnicas de análise das comunicações visando obter por procedimentos sistemáticos e objectivos de descrição do conteúdo das mensagens indicadores que permitam a inferência de conhecimentos relativos às condições de produção/recepção destas mensagens" (BARDIN, 2013, p. 44), configurou-se como procedimento relevante, sobretudo pela possibilidade de produção de um texto analítico no qual é possível apresentar o corpo textual dos documentos recolhidos de forma transformada.

\section{A construção do significado do contexto de atuação profissional}

Reconhecendo a diversidade do contexto brasileiro e respeitando as particularidades de cada instituição formadora, é preciso considerar, logo de partida, que este trabalho não intenciona fazer generalizações, mas, a partir dos elementos trabalhados, construir um processo reflexivo que problematize a relação com os contextos de atividade profissional e a sua consideração no processo de formação inicial desenvolvido pelas instituições formadoras.

Assim, o contexto profissional, caracterizado por sua singularidade, complexidade e pluralidade em suas interações e diversidades culturais; pela imprevisibilidade e dinamicidade de acontecimentos e necessidades, problematiza, a todo momento, a intervenção pedagógica (SILVA, 2011, p. 547) realizada pelos professores, interpelando para que esta seja mais adequada e relevante para a aprendizagem dos educandos.

Desta forma, conceber a formação de professores na perspectiva integrada significa, também, evidenciar a importância dos contextos profissionais como realidades situacionais, também, responsáveis pelo processo de formação inicial dos professores, uma vez que são neles que os licenciandos constroem suas primeiras experiências profissionais.

Os projetos analisados não explicitam claramente uma determinada concepção do contexto. No entanto, é possível inferir que ele é entendido a partir de duas perspectivas: alguns projetos o interpretam como "realidade integrada" ao contexto formativo e outros, como "realidade paralela" ao contexto formativo. 
No primeiro caso, fica evidente que a realidade do contexto de atuação profissional, com toda sua complexidade, deve permear inteiramente o processo formativo, de modo que este seja assumido, também, como espaço de formação, sendo apropriado pelas instituições de ensino superior como instância formativa, com a qual deve ser estabelecida uma relação horizontal, permeada pelo diálogo e pela cooperação, tendo consciência de que muitos saberes necessários à atuação profissional são construídos e consolidados lá, no contexto de atividade profissional, e não no interior das instituições de ensino superior, oficialmente responsáveis pela formação inicial dos professores.

A alternância progressiva entre tempo na universidade e no mundo do trabalho deverá caracterizar o processo formativo. (A-1) A escola e a universidade constituem um lugar onde o educando possa ensaiar um projeto de vida, comprometido com valores humanos e sociais que elevam a dignidade da pessoa humana. (B-3)

Zeichner (2010) propõe esta alternância entre contexto de formação e contexto de trabalho, ao longo de todo percurso de formação inicial, como procedimento metodológico fulcral na organização curricular da formação inicial de professores. É o que ele denomina de "terceiro espaço", caracterizado pela elaboração de espaços e tempos híbridos que devem reunir o conhecimento prático ao acadêmico de modo menos hierárquico e mais igualitário, tendo em vista a criação de novas oportunidades de aprendizagem para professores em formação, as quais são construídas por intermédio da relação dialética e compartilhada destes dois espaços formativos: a instituição de ensino superior e o contexto de atuação profissional.

No segundo caso, o contexto profissional tende a ser interpretado como uma "realidade paralela" ao contexto formativo. Ou seja, a formação deve acontecer, prioritariamente, na instituição de ensino superior e o contexto de atividade profissional é aquele espaço à parte que pode ser "utilizado" para que as teorias/metodologias estudadas no contexto da formação possam ser aplicadas no contexto profissional.

Assim, priorizar-se-á no âmbito da formação, uma sólida formação contemplando o diálogo fecundo entre diferentes áreas do conhecimento possibilitando ao acadêmico aplicar, no campo da educação, as contribuições de conhecimentos filosóficos, históricos, antropológicos, ambiental-ecológicos, psicológicos, linguísticos, sociológicos, políticos, econômicos, culturais. (E-1)

Esta situação é reveladora de concepções arraigadas e redutoras da formação e da atuação profissional do professor, pautadas pela supremacia da teoria em detrimento à prática, que se firma como um modelo de "fora para dentro", no qual o saber está, preferencialmente, entre os acadêmicos e não entre os professores da Educação Básica que, por vezes, acumulam saberes de experiência, os quais, nesta relação tradicional, são desconsiderados (FELÍCIO, 2014, p. 422). Estas concepções expressam diferentes formas de se efetivar a relação com o contexto profissional no currículo dos cursos de formação inicial de professores, sobretudo nos momentos da prática pedagógica e do estágio, em que tais instituições necessitam destes contextos, a fim de que o processo de formação seja efetivado e a certificação profissional se concretize. 
Identificamos que o formato desta relação com o contexto assume diferentes configurações nas propostas formativas analisadas. Uma, que como reflexo da primeira concepção de contexto identificada anteriormente, tende a estabelecer uma permanente articulação, proporcionando aos formandos possibilidades de construírem seu percurso formativo na integração entre esses dois espaços.

Permanente articulação entre formação teórica desenvolvida e realidade educacional vivenciada, a partir da compreensão de que a unidade teoria e prática ocorre numa abordagem da relação de interdependência e de mútua determinação entre ambas. A teoria, com efeito, é reelaborada a partir da prática, sendo que a validade da teoria é verificada pela própria prática. (D-3)

Nesta permanente articulação, sobretudo por explicitar a necessária relação de interdependência entre os dois contextos, formação e atividade profissional, torna-se evidente o reconhecimento das especificidades de cada contexto e a importância dos mesmos no processo de formação inicial de professores, uma vez que "dificilmente poderemos entender uma formação que desligue o conhecimento do contexto da ação." (SILVA, 2011, p. 607).

Da mesma forma, ao explicitar que este processo depende da determinação de ambas as instituições, entendemos ser necessário interpelar o próprio contexto profissional para o reconhecimento de sua natureza e responsabilidade formativa. Ou seja, é necessário conferir ao contexto de atuação profissional o status formativo que Ihe é inerente, a fim de que ele ultrapasse sua postura passiva, muitas vezes limitada no acolhimento dos licenciandos para uma prática pedagógica e/ou estágio que venha "contribuir" com o seu complexo cotidiano. Outro formato identificado nos mostra a relação com o contexto sendo assumida na perspectiva de que se pode resolver os problemas imediatos, tanto dos licenciandos, quanto do contexto profissional. Esta forma de relação reflete uma representação que se construiu, ao longo do tempo, de uma relação unilateral entre a instituição de ensino superior e o contexto de atividade profissional, no qual o primeiro se apresenta como superior ao segundo, com a capacidade de resolver os problemas deste, a partir dos conhecimentos teóricos trabalhados em seu interior.

Todo o processo de estágio será desenvolvido em articulação com os profissionais das diferentes instituições/contextos onde este deverá ocorrer. O estágio deverá atender às necessidades de formação do Pedagogo, bem como às necessidades dessas instituições/contextos. (D-3)

Este modo de se relacionar com o contexto evidencia uma perspectiva formativa que vai da teoria à prática, mediante uma abordagem dedutiva, "uma vez que os conteúdos são diretamente dedutíveis do conhecimento científico disponível" (KORTHAGEN, 2009, p. 40) e transportados para o contexto de atuação profissional, a fim de que seus "problemas" sejam resolvidos, colocando assim este contexto em um plano inferior.

O terceiro aspecto evidenciado nos mostra uma relação com o contexto em que a relevância está na prática do outro. Ou seja, esta prática passa a ser assumida como um objeto para o qual se deve lançar o foco, perceber as limitações, fazer julgamentos e, a partir daí, desencadear processos de estudo e reflexão. 
O objetivo da prática pedagógica é possibilitar aprendizagem prática em situação, ou seja, a partir da realidade, tomando os eventos e aspectos dificultadores da prática pedagógica do professor e da escola como fontes de aprendizado, uma vez que esses aspectos e eventos são tomados como objeto de estudo e reflexão pelos residentes, orientados por seus preceptores. (D-4)

Esta forma de relação com os contextos profissionais desloca o foco de atenção do sujeito que está a iniciar sua profissão (a quem a prática pedagógica e o estágio são atividades fundamentais) para aquele que já está no exercício da profissão. Este movimento é um dos principais motivos que alimenta certa resistência no total acolhimento dos licenciandos, por parte dos profissionais que estão nos contextos, uma vez que esses profissionais se sentem fragilizados, sabendo que as limitações da prática profissional serão, em algum momento, evidenciadas.

Desta forma, percebemos que a ênfase nestas limitações é interpretada, por esses contextos, como um aspecto negativo das práticas pedagógicas e dos estágios desenvolvidos pelos formandos, sobretudo porque elas passam a ser objeto de análise nas instituições de formação, a partir de uma perspectiva interpretativa (FREIRE, 2001) que, muitas vezes, desconsidera a complexidade do contexto, as condições nas quais tais práticas são produzidas e a dimensão coletiva da prática pedagógica, centrando-se na ação individualizada de um determinado profissional. Considerando que a profissionalidade docente, ao longo da história, se firmou como uma atividade desenvolvida no isolamento, em que a principal relação estabelecida é a do professor com seus educandos, em um espaço delimitado da sala de aula, afirmamos que a ação do professor se caracteriza como ação individualizada, que é reforçada pela própria organização institucional e curricular que desfavorece a relação dos professores entre si, para um trabalho colaborativo; e com profissionais de outras instituições, para um trabalho participativo.

No caso específico da formação de professores, em que, no momento da prática e/ou estágio, a relação entre a instituição de ensino superior e o contexto de atividade profissional se efetiva na relação professor formador - licenciando - professor, faz-se necessário que ela "não se esgote no apoio à supervisão do estagiário, mas se encaminhe para a construção de uma comunidade de prática." (ROLDÃO, 2005, p.23). Esta comunidade de prática é definida por Wenger (2002) como sendo um grupo de pessoas que compartilham um determinado interesse, que se juntam para desenvolver conhecimento em torno deste tópico definido, que interagem regularmente, recriando práticas melhores.

Entendida como possibilidade de reconfigurar a relação entre a instituição de formação e o contexto de atividade profissional, no caso específico da formação inicial de professores, em que o formando se apresenta como sujeito imprescindível nos dois contextos, a comunidade de prática pode ser a expressão de uma parceria mais efetiva entre estas instituições, como declarada em diversos projetos.

Destaca-se que esse projeto implica em parcerias mais efetivas entre a Universidade e as Escolas, entrelaçadas com posturas críticas e investigativas que deverão ser conduzidas pela organização interna nas disciplinas por meio da execução de projetos integrados, seminários de estudos, palestras, em todos os semestres. (E-3) 
No entanto, uma questão fundamental na organização de comunidade de prática é a mudança de postura, no sentido de romper este paradigma de formação que sustenta um status superior às instituições de ensino superior, legitimando-as, inclusive para definir ações e intervenções no contexto de atividade profissional sem que este seja, previamente, considerado em sua complexidade. Deste ponto de vista, é necessário compreender que

\begin{abstract}
a formação inicial só será eficaz se se transformar nesta formação em imersão, feita com as escolas, que, por um lado, coloque os futuros professores em situação que alimente o seu percurso de formação inicial e, por outro, converta as escolas, os jardins de infância, os contextos de trabalho em que os nossos profissionais vão actuar, em outras tantas unidades de formação que conosco, ensino superior e investigadores, construam parcerias de formação/investigação, desenvolvidas dentro da acção quotidiana da escola, transformando-a em espaço real de formação profissional permanente. (ROLDÃO, 2007, p. 40).
\end{abstract}

Desta forma, entender que a formação e o desenvolvimento profissional devem estar centrados no contexto de atuação profissional supõe assumir que as instituições de ensino superior não são "únicas" na formação inicial de professores. Assumir que elas dependem deste contexto é um grande avanço em direção à construção de comunidades de práticas, de redes de aprendizagem, parcerias entre os diversos agentes envolvidos no processo de formação de professores (DAY, 2001).

\title{
Em caráter (in)conclusivo...
}

É preciso entender que a relação entre a Universidade e a Escola de Educação Básica, na formação inicial de professores, é um processo que se constrói em meio a complexas tensões que tendem a pender hora para a dimensão teórica, hora para a dimensão prática; hora para o lado da universitarização, hora para o da escolarização. Entretanto, buscar o equilíbrio de modo que o licenciando seja preparado para o desenvolvimento de sua profissionalidade, sendo-lhe garantido as experiências do contexto e também o conhecimento teórico (LUDKE; CRUZ, 2005).

Desejamos que este equilíbrio seja resultado de uma relação mais igualitária entre esses dois contextos e menos hierárquica nas relações profissionais e formativas, de modo que ambos os contextos se constituam como espaços e tempos formativos de igual importância, porém com naturezas peculiares.Embora as análises realizadas neste trabalho indiquem avanços nesta relação, sobretudo no que diz respeito à concepção do contexto de atividade profissional e da relação estabelecida com ele por parte da Universidade, esperamos ações e iniciativas mais incisivas de ambos os contextos de modo que os licenciandos, futuros professores, possam saber administrar os diferentes saberes, construídos em diferentes lugares (TARDIF, 2002) e situações.

Dentre muitas questões, desejamos que a Universidade confira ao contexto de atividade profissional o status formativo que lhe é devido; que construa com o contexto de atividade profissional uma relação que perpassa todo o curso e não 
apenas os momentos pontuais da prática pedagógica ou do estágio; e que ofereça condições de trabalho do professor formador responsável por construir uma relação formativa com a Escola de Educação Básica.

De igual modo, esperamos que a Escola de Educação Básica se assuma como instituição co-formadora de futuros professores; que compreenda o seu complexo contexto como elemento formativo e que invista na formação continuada de seus professores, de modo que os mesmos participem do processo formativo dos futuros professores.

Assim, faz-se necessário que esses dois contextos lancem juntos um olhar para a formação inicial de professores, de caráter crítico-político-intencional, a partir de uma perspectiva formativa integrada, de modo que o movimento de alternância a ser realizado pelo licenciando entre os dois contextos formativos se constitua como um processo significativo e significante.

\section{Referências}

ALONSO, L. Perfil profissional e projecto de formação. In: LOPES, A. (org.). De uma escola a outra: Temas para pensar a formação inicial de professores. Porto: Edições Afrontamento / CIIE, 2007, p. 43-50.

ALONSO, L.; SILVA, C. Questões críticas acerca da construção de um currículo formativo integrado. In: ALONSO, L.; ROLDÃO, M. C. (coords.). Ser Professor do $\mathbf{1}^{\circ}$ Ciclo: Construindo a Profissão. Coimbra: Livraria Almedina / Universidade do Minho - Centro de Estudos da Criança, 2005, p. 43-63.

BARDIN, L. Análise de Conteúdo. (5. ed.). Lisboa: Edições 70, 2013.

BRASIL. Ministério da Educação. Conselho Nacional de Educação. Parecer CNE/ CP 009/2001. Diretrizes Curriculares Nacionais para a Formação de Professores da Educação Básica, em nível superior, curso de licenciatura, de graduação plena. Diário Oficial da União, Brasília, DF, 18 jan. 2002. Seção 1, p. 31.

BRASIL. Ministério da Educação. Conselho Nacional de Educação. Resolução CNE/CP 1/2006. Institui Diretrizes Curriculares Nacionais para o curso de graduação em Pedagogia, Licenciatura. Diário Oficial da União, Brasília, DF, 16 de maio de 2006, Seção 1, p. 11.

BRASIL. Ministério da Educação. Conselho Nacional de Educação. Resolução CNE/CP 2/2015. Define as Diretrizes Curriculares Nacionais para a formação inicial em nível superior (cursos de licenciatura, cursos de formação pedagógica para graduados e cursos de segunda licenciatura) e para a formação continuada. Diário Oficial da União, Brasília, DF, 2 de julho de 2015, Seção 1, p. 8-12.

DAY, C. Desenvolvimento Profissional de Professores: os desafios da aprendizagem permanente. Porto: Porto Editora, 2001.

ESTEVES, M. Análise de Conteúdo. In: LIMA, J. A.; PACHECO, J. A. Fazer Investigação: Contributos para a elaboração de dissertações e teses. Porto: Porto Editora, 2006. p. 105-126.

ESTRELA, M. T.; ESTRELA, A. IRA - Investigação, Reflexão, Acção e Formação de Professores. 
Porto: Porto Editora, 2001.

FELÍCIO, H. M. S. O PIBID como "terceiro espaço" de formação inicial de professores. Diálogo Educacional. Curitiba, v. 14, n. 42, maio/ago, 2014. p. 415-434.

FLICK, U. Métodos Qualitativos na Investigação Científica. Lisboa: Monitor, 2005.

FLORES, Maria Assunção. Algumas reflexões em torno da formação inicial de professores. Educação. Porto Alegre, v. 33, n. 3, p. 182-188, 2010.

FORMOSINHO, J. Academização da formação de professores. In: FORMOSINHO, J. (coord.). Formação de Professores: Aprendizagem profissional e acção docente (pp. 73-92). Porto: Porto Editora, 2009.

FREIRE, A. M. Concepções orientadoras do processo de aprendizagem do ensino nos estágios pedagógicos. Colóquio: modelos e práticas de formação inicial de professores, Faculdade de Psicologia e de Ciências da Educação, Universidade de Lisboa, 2001. Acesso em 06 de agosto de 2014, de http://www.educ.fc.ul.pt/recentes/mpfip/pdfs/afreire.pdf.

KORTHAGEN, F. A prática, a teoria e a pessoa na aprendizagem profissional ao longo da vida. In: FLORES, M. A.; SIMÃO, A. V. Aprendizagem e Desenvolvimento Profissional de Professores: Contextos e Perspectivas. Manguarde, Portugal: Edições Pedago, 2009. p. 39-60.

LUDKE, M.; CRUZ, G. B. Aproximando universidade e escola de educação básica pela pesquisa. Cadernos de Pesquisa. São Paulo, v. 35, n. 125, maio/ago, 2005, p. 81-109.

MUÑOZ, J. M. La formación del profesorado y la garantía del derecho a una buena educación para todos. In: ESCUDERO, J. M.; GÓMEZ, A. L. (editores). La Formación del Profesorado y la Mejora de la Educación. Barcelona: Ediciones Octaedro, 2006, p. 21-51.

NÓVOA, A. Professores: imagens do futuro presente. Lisboa: Educa, 2009.

PIMENTEL, A. O método da análise documental: seu uso numa pesquisa historiográfica. Cadernos de Pesquisa. n. 114, 2001. p. 179-195.

ROLDÃO, M. C. A formação como projecto: do plano-mosaico ao currículo como projecto de formação. In: CAMPOS, B. P. (org.). Formação Profissional de Professores no Ensino Superior. Porto: Porto Editora, 2001. p. 6-20.

ROLDÃO, M. C. Formação de Professores, construção do saber profissional e cultura da profissionalização: que triangulação? In: ALONSO, L.; ROLDÃO, M. C. Ser professor do $\mathbf{1}^{\circ}$ Ciclo: Construindo a Profissão (pp. 13-25). Coimbra: Almedina, 2005. p. 13-25.

ROLDÃO, M. C. Formar para a excelência profissional - pressupostos e rupturas nos níveis inicias da docência. Educação \& Linguagem. n¹5, 2007. p. 18-42.

SACRISTÁN, G. (2010). Qué significa el currículum? In: SACRISTÁN, J. G. Saberes e incertidumbres sobre el currículum. Madrid: Ediciones Morata, 2010. p. 21-43.

SILVA, C. M. Tornar-se Professor: Desenvolvimento Curricular e Construção do Conhecimento Profissional. (Vol. I e II). Tese de Doutoramento. Braga: Universidade do Minho/Instituto de Educação, 2011. 
TARDIF, M. Saberes docentes e formação profissional. 2. ed. Petrópolis: Vozes, 2002.

WENGER, E. Cultivating communities of practice: a guide to managing knowledge. Boston: Harvard Business School Press, 2002.

ZEICHNER, Ken. Rethinking the connections between campus courses and field experiences in College - and University-Based Teacher Education. Journal of Teacher Education. v. 61 (1-2). 2010. p. 88-99.

Artigo recebido em: 01/11/2018

Aprovado em: 21/03/2019

Contato para correspondência:

Helena Maria dos Santos Felício. E-mail: hsfelicio@gmail.com

Notas

1 Os Projetos Pedagógicos excluídos dizem respeito a cursos que são oferecidos, especificamente, para professores que exercem a profissão, mas que não possuem o Ensino Superior. 